\title{
EFEITO DO TRATAMENTO DE BACELOS DE VIDEIRA 'RED GLOBE' NO CONTROLE DO CANCRO BACTERIANO CAUSADO POR Xanthomonas campestris pv. viticola ${ }^{1}$
}

\author{
CARINE ROSA NAUE², MARIA ANGÉLICA GUIMARÃES BARBOSA ${ }^{3}$, \\ DIÓGENES DA CRUZ BATISTA ${ }^{4}$, ELINEIDE BARBOSA DE SOUZA ${ }^{5}$, \\ ROSA DE LIMA RAMOS MARIANO ${ }^{6}$
}

RESUMO - A disseminação de Xanthomonas campestris pv. viticola (Xcv), agente do cancro bacteriano da videira, ocorre, dentre outras formas, por meio de mudas e bacelos infectados. Foi estudada a obtenção de material propagativo livre do patógeno, testando a eficiência do tratamento de bacelos com termoterapia, bactericidas e sanitizantes. Os isolados de $X c v$ foram testados quanto à patogenicidade e realizado o teste de sensibilidade in vitro aos produtos, em diferentes concentrações. A erradicação de $X c v$ em bacelos de videira foi testada em experimentos com termoterapia $\left(50^{\circ} \mathrm{C}\right.$ por 30 e $40 \mathrm{~min} ; 53^{\circ} \mathrm{C}$ por 5 e 10 min); bactericidas [oxitetraciclina+sulfato de cobre $\left(150+2.000 ; 165+2.200 ; 180+2.400\right.$ e $195+2.600 \mathrm{mg} \mathrm{L}^{-1} \mathrm{de}$ $\left.\mathrm{H}_{2} \mathrm{O}\right)$ e oxitetraciclina $\left(600 ; 700 ; 800\right.$ e $\left.900 \mathrm{mg} \mathrm{L}^{-1}\right)$ ]; e sanitizantes [cloreto de dodecildimetil amônio (600; $1.200 ; 1.800 ; 2.400$ e $\left.3.000 \mu \mathrm{L} \mathrm{L}^{-1}\right)$; hipoclorito de sódio $\left(5.000 ; 10.000 ; 20.000 ; 30.000\right.$ e $\left.40.000 \mu \mathrm{L} \mathrm{L}^{-1}\right) \mathrm{e}$ cloreto de benzalcônio $\left(125 ; 167 ; 250 ; 334\right.$ e $\left.\left.500 \mu \mathrm{L} \mathrm{L}^{-1}\right)\right]$. Foram avaliados período de incubação, incidência e severidade da doença. O bactericida oxitetraciclina e os sanitizantes cloreto de dodecildimetil amônio e hipoclorito de sódio proporcionaram os maiores halos de inibição de Xcv in vitro. No entanto, apesar dos diversos tratamentos testados, não foi possível recomendar tratamento termoterápico ou produto que erradicasse $X c v$ de bacelos infectados. Porém, ficou confirmada a grande importância destes na disseminação do agente do cancro bacteriano da videira.

Termos para Indexação: Vitis sp., termoterapia, bactericida, sanitizante, erradicação.

\section{EFFECT OF TREATMENT OF 'RED GLOBE' VINE CUTTINGS ON THE CONTROL OF BACTERIAL CANKER CAUSED BY Xanthomonas campestris pv. viticola}

\begin{abstract}
The spread of Xanthomonas campestris pv. viticola (Xcv), causal agent of grapevine bacterial canker, occurs among other ways, through infected plants and grapevine cuttings. It was studied how to obtain propagation material free of $X c v$ testing the effectiveness of treatments of cuttings using thermotherapy, bactericides and sanitizers. The $X c v$ isolates were tested for pathogenicity and in vitro sensitivity to bactericides and sanitizers at different concentrations. The eradication of $X c v$ on cuttings was tested in experiments with thermotherapy $\left(50^{\circ} \mathrm{C}\right.$ for 30 and $40 \mathrm{~min} ; 53^{\circ} \mathrm{C}$ for 5 and $\left.10 \mathrm{~min}\right)$; bactericides [oxytetracycline + copper sulphate $\left(150+2000,165+2200,180+2400\right.$ and $195+2600 \mathrm{mg} \mathrm{L}^{-1}$ of $\left.\mathrm{H}_{2} \mathrm{O}\right)$ and oxytetracycline $(600,700,800$ and $\left.900 \mathrm{mg} \mathrm{L}^{-1}\right)$ ] and sanitizers [dodecyldimethyl ammonium chloride $\left(600,1200,1800,2400\right.$ and $\left.3000 \mu \mathrm{L}^{-1}\right)$ sodium hypochlorite (5000, 10000, 20000, 30000 and $\left.40000 \mu \mathrm{L} \mathrm{L}^{-1}\right)$ and benzalkonium chloride (125, 167 , 250, 334 and $\left.\left.500 \mu \mathrm{L}^{-1}\right)\right]$. We evaluated the incubation period, the incidence and severity of disease. The bactericidal oxytetracycline and sanitizers dodecyldimethyl ammonium chloride and sodium hypochlorite provided the largest zones of inhibition, in vitro. However, despite the several treatments tested we cannot recommend an efficient condition of temperature/time, and concentrations of bactericides and sanitizers capable of eradicating $X c v$ from infected grapevine cuttings, thus confirming their great importance for the spread of grapevine bacterial canker.

Index terms: Vitis sp., thermotherapy, bactericide, sanitizing, eradication.

\footnotetext{
${ }^{1}$ (Trabalho 435-13). Recebido em: 27-11-2013. Aceito para publicação em: 14-07-2014. ${ }^{3}$ Eng. Agr. Dra. Embrapa Semiárido E-mail: angelica.guimaraes@embrapa.br

${ }^{4}$ Eng. Agr. Dr. Embrapa Semiárido. E-mail: diogenes.batista@embrapa.br

${ }^{5}$ Eng. Agr. Prof. Depto de Biologia/Microbiologia, Universidade Federal Rural de Pernambuco, E-mail: elineidebs@yahoo.com.br

${ }^{6}$ Eng. Agr. Prof. Depto de Agronomia/ Fitossanidade, Universidade Federal Rural de Pernambuco E-mail: rrmbac@gmail.com
}

${ }^{2}$ Bióloga, Doutoranda Depto de Agronomia/Fitossanidade, Universidade Federal Rural de Pernambuco, E-mail: crnaue@yahoo.com.br
\end{abstract}




\section{INTRODUÇÃO}

A viticultura tem destaque no Brasil principalmente no estado do Rio Grande do Sul e no Vale do Submédio São Francisco (Petrolina$\mathrm{PE} / J u a z e i r o-B A)$. A rápida expansão da viticultura neste Vale originou problemas fitossanitários dentre os quais o cancro bacteriano da videira, causado por Xanthomonas campestris pv. viticola (Nayudu) Dye. $(X c v)$, que é a bacteriose mais importante para essa cultura no Brasil. Os sintomas do cancro bacteriano nas folhas são pequenas lesões necróticas, angulares, esparsas, que coalescem causando amplo crestamento foliar. Manchas alongadas ocorrem nas nervuras, pecíolos e ramos, com formação de cancros e descoloração na região vascular. Nas ráquis, observam-se manchas e cancros; e nas bagas, lesões pequenas, escuras e arredondadas (MALAVOLTA et al., 1999).

O patógeno sobrevive em videira e outras hospedeiras infectadas, com ou sem sintomas (NASCIMENTO; MARIANO, 2004; PEIXOTO et al., 2007) e em restos culturais (SILVA et al., 2012). Destas fontes de inóculo, $X c v$ é disseminada durante os tratos culturais por respingos de água de chuva e irrigação, pulverizações, ferramentas de cultivo não desinfestadas, roupas e veículos (NASCIMENTO; MARIANO, 2004). No entanto, a disseminação do patógeno é feita a média e longa distância, principalmente por mudas e bacelos contaminados. O patógeno é uma praga quarentenária presente (A2), encontrada apenas nos Estados da Bahia, Ceará e Pernambuco (RODRIGUES NETO et al., 2011), mas detectada e erradicada dos Estados de Goiás, Paraná, Piauí, Roraima e São Paulo (RODRIGUES NETO et al., 2011; TOMAZ et al., 2011).

Atualmente, no Vale do Submédio São Francisco, dentre outras cultivares suscetíveis, a grande maioria dos parreirais de 'Red Globe' está infectada com $X c v$. Uma das medidas de controle mais utilizada é evitar a poda de produção durante o período chuvoso. No entanto, o descumprimento desta medida tem como consequência o emprego de grande quantidade de fungicidas cúpricos, sozinhos ou em combinação com ditiocarbamatos, aumentando o custo de produção da cultura.

Tentando minimizar os prejuízos causados pelo cancro bacteriano e desconhecendo-se um método único eficiente de controle, recomenda-se um conjunto de medidas, incluindo as que interferem na introdução e na disseminação do patógeno, a exemplo do uso de material propagativo livre de $X c v$. Atualmente, a técnica de cultura de tecidos é muito utilizada para propagação de plantas livres de patógenos e, no caso da videira, possibilita a obtenção de plantas com boa regeneração e livres de Xcv (SILVA et al., 2013). No entanto, requer longo tempo e ainda não está sendo utilizada em larga escala no Vale do Submédio São Francisco. Desta forma, o tratamento de bacelos pode ser uma alternativa eficiente e mais rápida para a produção de material propagativo isento do patógeno.

A termoterapia foi utilizada para tratamento de órgãos propagativos de cana-deaçúcar (FERNANDES JR. et al., 2010) e videira (MAHMOODZADEH et al., 2003), visando à erradicação de Leifsonia xyli subsp. xyli e Rhizobium vitis (sin. Agrobacterium vitis), respectivamente; e a termoterapia, aliada a fungicidas, foi testada para o tratamento de estacas de videira, visando ao controle de doenças fúngicas (GRAMAJE et al., 2009a; GRAMAJE et al., 2009b). Para o controle do cancro bacteriano, foram testados, no tratamento de bacelos infectados, produtos químicos (oxitetraciclina, sulfato de cobre, amônia quaternária, cloranfenicol e cobre líquido) e termoterapia (água quente a $48-50^{\circ} \mathrm{C} / 15 \mathrm{~min}$ ), verificando-se em todos os tratamentos os sintomas da doença em pecíolos e folhas (LIMA; MASHIMA, 2000).

Diante do exposto e sabendo-se da importância da utilização de material propagativo sadio no controle do cancro bacteriano, este trabalho teve como objetivo avaliar a eficiência dos tratamentos de bacelos de videira para a erradicação de $X c v$, utilizando-se de termoterapia, bactericidas e sanitizantes.

\section{MATERIAL E MÉTODOS}

Os experimentos in vitro foram realizados no Laboratório de Fitopatologia da Embrapa Semiárido e os in vivo foram conduzidos em três locais diferentes: viveiro de mudas do Laboratório de Biotecnologia; viveiro de mudas da Estação Experimental de Bebedouro; e casa de vegetação do Laboratório de Fitopatologia, todos da Embrapa Semiárido, Petrolina-PE, no período de janeiro a maio de 2012.

Preparo das suspensões de Xanthomonas campestris pv. viticola e concentração do inóculo

$\mathrm{O}$ isolado de $X c v$ foi reativado e testado quanto à patogenicidade pelo método de picada na haste e no pecíolo (PEIXOTO et al., 2007), em mudas da variedade Red Globe, e as culturas foram mantidas em meio NYDA (dextrose 10, extrato de carne 3, extrato de levedura 5, peptona 5 e ágar $18 \mathrm{~g} \mathrm{~L}^{-1}$ ). Para o preparo do inóculo, o isolado foi transferido para placas de Petri contendo o mesmo meio durante 48 
horas a $28^{\circ} \mathrm{C}$. A suspensão bacteriana foi preparada em água destilada esterilizada (ADE), sendo a concentração ajustada em fotocolorímetro para $\mathrm{A}_{570}$ $=0,4$, que corresponde a $10^{8} \mathrm{UFC} \mathrm{mL}^{-1}$ (PEIXOTO et al., 2007). O isolado utilizado pertence à Coleção de Bactérias Fitopatogênicas do Laboratório de Fitopatologia da Embrapa Semiárido.

Sensibilidade in vitro de Xanthomonas campestris pv. viticola a bactericidas e sanitizantes

Foram testados quatro bactericidas e três sanitizantes. Para os bactericidas, foram realizados dois ensaios. Primeiramente, foram testados os bactericidas em diferentes concentrações: oxitetraciclina+estreptomicina $(18+180 ; 30+300$; $36+360$ e $\left.45+450 \mathrm{mg} \mathrm{L}^{-1}\right)$; oxitetraciclina + sulfato de cobre $(45+600 ; 90+1.200 ; 120+1.600$ e $150+2.000 \mathrm{mg}$ $\left.\mathrm{L}^{-1}\right)$; casugamicina $\left(60 \mu \mathrm{L} \mathrm{L}^{-1}\right)$ e oxitetraciclina (400; 480 e $600 \mathrm{mg} \mathrm{L}^{-1}$ ), frente a $X c v$. Devido à inexistência de bactericidas registrados para o controle do cancro bacteriano da videira, as concentrações utilizadas foram aquelas recomendadas nos rótulos dos produtos para controle de outras fitobacterioses. Todas as soluções dos produtos foram feitas em água destilada ou ADE.

Para o segundo ensaio, foram testados os dois bactericidas mais eficientes, porém em concentrações superiores às utilizadas anteriormente: oxitetraciclina+sulfato de cobre $(150+2.000 ; 165+2.200 ; 180+2.400 ; 195+2.600 \mathrm{e}$ $\left.210+2.800 \mathrm{mg} \mathrm{L}^{-1}\right)$ e oxitetraciclina $(600 ; 700 ; 800$; 900 e $1.000 \mathrm{mg} \mathrm{L}^{-1}$ ) frente a Xcv.

Para os sanitizantes, foram testados três produtos e cinco concentrações: cloreto de dodecildimetil amônio $(600 ; 1.200 ; 1.800 ; 2.400$ e $3.000 \mu \mathrm{L} \mathrm{L}^{-1}$ ), hipoclorito de sódio (2.500; $5.000 ; 7.500 ; 10.000$ e $\left.12.500 \mu \mathrm{L} \mathrm{L}^{-1}\right)$ e cloreto de benzalcônio $\left(125 ; 167 ; 250 ; 334\right.$ e $\left.500 \mu \mathrm{L} \mathrm{L}^{-1}\right)$ frente a Xcv.

A metodologia utilizada foi a do antibiograma, descrita por ROMEIRO (2005) modificada. Em placas de Petri, foi vertida uma camada básica de ágar-ágar (1,8\% de ágar), com aproximadamente $1 \mathrm{~mm}$ de espessura. Posteriormente, verteu-se uma sobrecamada de meio NYDA semissólido $(0,9 \%$ de ágar), acrescido da suspensão de $X c v\left(10^{8}\right.$ UFC $\mathrm{mL}^{-1}$ ), na proporção de $200 \mu \mathrm{L} 10 \mathrm{~mL}^{-1}$. Após a solidificação da sobrecamada, os discos de papel de filtro foram embebidos nas diferentes concentrações dos produtos testados e colocados sobre a superfície do meio. Em cada placa, foram colocados quatro discos, com a mesma concentração, dispostos de forma equidistante. A testemunha consistiu em discos embebidos em ADE. As placas contendo a suspensão de $X c v$ foram incubadas a $28^{\circ} \mathrm{C}$ e, após 48 horas, com o auxílio de uma régua milimetrada, mediu-se o diâmetro do halo de inibição, em dois sentidos opostos, estabelecendo-se a média.

$\mathrm{O}$ delineamento experimental utilizado foi o inteiramente casualizado, com cinco repetições, sendo cada uma constituída de uma placa de Petri contendo quatro discos. A análise dos dados foi realizada no programa The SAS System version 9.0 (SAS Institute Inc. Cary, NC, 27513, USA, 2002), e as médias foram comparadas pelo teste de Tukey, a $5 \%$ de significância.

Tratamento de bacelos de videira com termoterapia, bactericidas e sanitizantes visando à erradicação de Xanthomonas campestris pv. viticola

No mês de janeiro de 2012, foram realizadas as coletas de ramos de uva de mesa, da variedade Red Globe, com sintomas da doença, em áreas produtoras no Projeto de Irrigação de Bebedouro, Petrolina-PE. Imediatamente após a coleta, os ramos foram reduzidos a bacelos, com 15 a $20 \mathrm{~cm}$ de comprimento, contendo três gemas e um diâmetro médio de $6 \mathrm{~mm}$. Em seguida, os bacelos foram imersos verticalmente em uma lâmina de água de torneira de aproximadamente $10 \mathrm{~cm}$, por 48 horas, para facilitar o enraizamento, e após este período, os mesmos foram submetidos aos tratamentos.

Os tratamentos de termoterapia foram realizados em um aparelho de banho-maria (Cien Tec 268) com termostato, onde os bacelos foram imersos em água, de acordo com cada tratamento: $50^{\circ} \mathrm{C}$ por 30 minutos (T1); $50^{\circ} \mathrm{C}$ por 40 minutos (T2); $53^{\circ} \mathrm{C}$ por 5 minutos (T3), e $53^{\circ} \mathrm{C}$ por 10 minutos (T4). Dois bactericidas foram testados em quatro diferentes concentrações: oxitetraciclina+sulfato de cobre $(150+2.000 ; 165+2.200 ; 180+2.400$ e $195+2.600$ $\left.\mathrm{mg} \mathrm{L}^{-1}\right)$ e oxitetraciclina $(600 ; 700 ; 800$ e $900 \mathrm{mg}$ $\left.\mathrm{L}^{-1}\right)$. Os três sanitizantes testados em cinco diferentes concentrações foram: cloreto de dodecildimetil amônio (600, 1.200; 1.800; 2.400 e $\left.3.000 \mu \mathrm{L} \mathrm{L}^{-1}\right)$; hipoclorito de sódio $(2.500 ; 5.000 ; 7 ; 500 ; 10.000$ e $\left.12500 \mu \mathrm{L} \mathrm{L} \mathrm{L}^{-1}\right)$ e cloreto de benzalcônio (125;167; $250 ; 334$ e $\left.500 \mu \mathrm{L} \mathrm{L}^{-1}\right)$. Em bandejas plásticas (40 × $28 \times 10 \mathrm{~cm})$, os bacelos foram imersos nas suspensões dos diferentes produtos, por 60 minutos. A testemunha, para todos os tratamentos, consistiu em bacelos imersos em água de torneira pelo tempo respectivo.

Logo após os tratamentos, os bacelos foram levados para os viveiros e casa de vegetação com temperatura controlada e plantados em sacos de polietileno $(10 \times 20 \mathrm{~cm})$, contendo solo natural. Todas as plantas foram irrigadas com auxílio de mangueira; a temperatura e a umidade relativa foram registradas, 
e as médias foram calculadas.

As avaliações dos componentes epidemiológicos tiveram início a partir da brotação dos bacelos. A erradicação do patógeno foi avaliada pela presença ou ausência de sintomas nas plantas. Os componentes epidemiológicos observados foram: a) período de incubação, representado pelo número de dias entre a brotação do bacelo e o surgimento dos sintomas da doença. Plantas que não apresentaram sintomas tiveram o período de incubação ajustado para o período de avaliação total, acrescido de um dia; b) incidência da doença, calculada ao final do experimento, pelo percentual de folhas com sintomas em relação ao número total de folhas da planta; e c) severidade, estimada com o auxílio de escala diagramática (NASCIMENTO et al., 2005) para cada folha infectada da planta, ao final do experimento. $\mathrm{O}$ período de incubação foi avaliado durante 15 semanas, diariamente, e ao final deste período, a incidência e a severidade foram avaliadas.

Os experimentos com termoterapia, bactericidas e sanitizantes foram realizados em viveiro e casa de vegetação. $\mathrm{O}$ experimento com termoterapia foi realizado duas vezes em casa de vegetação e quatro vezes em viveiro; o de bactericidas foi realizado duas vezes em casa de vegetação e duas em viveiro; enquanto aquele com sanitizantes foi realizado duas vezes em viveiro e uma em casa de vegetação.

O delineamento experimental para todos os experimentos foi o inteiramente casualizado. Os experimentos com termoterapia, antibióticos e sanitizantes foram constituídos por cinco, nove e dezesseis tratamentos, respectivamente. Todos os tratamentos tiveram sete repetições, sendo cada repetição representada por um bacelo.

Os dados foram submetidos ao teste de homogeneidade de variâncias (teste de Levene), submetidos à análise de variância (ANOVA) e, quando significativa, comparação das médias pelo teste de Tukey, a 5\% de probabilidade. Quando houve homogeneidade, os resultados foram analisados em conjunto, durante a análise de variância. Empregouse o programa SAS System v. 9.0 em todas as análises estatísticas.

\section{RESULTADOS E DISCUSSÃO}

Nos três locais anteriormente citados, onde os experimentos in vivo foram realizados, as condições climáticas durante o período de janeiro a maio de 2012 foram adequadas ao desenvolvimento do cancro bacteriano. As médias das variáveis climáticas desses meses, para os viveiros, foram: temperatura média de $27,4^{\circ} \mathrm{C}$; temperatura máxima de $33,4^{\circ} \mathrm{C}$; temperatura mínima de $21,9^{\circ} \mathrm{C}$; umidade relativa média de $52,7 \%$; umidade relativa máxima de $76,2 \%$; umidade relativa mínima de $31,1 \%$; e precipitação de $0,34 \mathrm{~mm}$. Para casa de vegetação, foram: temperatura média de $25,6^{\circ} \mathrm{C}$; temperatura máxima de $31,5^{\circ} \mathrm{C}$; temperatura mínima de $19,8^{\circ} \mathrm{C}$; umidade relativa média de $57 \%$; umidade relativa máxima de $80 \%$; umidade relativa mínima de $34 \%$.

Sintomas do cancro bacteriano da videira foram observados em plantas obtidas de bacelos submetidos a todos os tratamentos dos experimentos com termoterapia, bactericidas e sanitizantes.

No primeiro experimento in vitro, $\mathrm{Xcv}$ foi sensível aos bactericidas oxitetraciclina e oxitetraciclina+sulfato de cobre (dados não apresentados). No segundo experimento, oxitetraciclina proporcionou os maiores halos de inibição de $X c v$, sendo que as cinco concentrações testadas, inclusive a menor delas $\left(600 \mathrm{mg} \mathrm{L}^{-1}\right)$, diferiram estatisticamente da maior concentração de oxitetraciclina + sulfato de cobre $(210+2.800 \mathrm{mg}$ $\left.\mathrm{L}^{-1}\right)$ (Tabela 1).

Os sanitizantes cloreto de dodecildimetil amônio e hipoclorito de sódio apresentaram maior eficácia na inibição de $X c v$, à exceção da concentração de $2.500 \mu \mathrm{L} \mathrm{L}^{-1}$ de hipoclorito de sódio. O patógeno não foi inibido pelas três menores concentrações testadas do cloreto de benzalcônio $(125,167$ e 250 $\mu \mathrm{L} \mathrm{L}^{-1}$ ) (Tabela 2).

No experimento com termoterapia, tanto no viveiro quanto na casa de vegetação, não houve diferença significativa $(\mathrm{P} \leq 0,05)$ entre a testemunha e os tratamentos, $50^{\circ} \mathrm{C}$ por 30 minutos; $50^{\circ} \mathrm{C}$ por 40 minutos; $53^{\circ} \mathrm{C}$ por 5 minutos; e $53^{\circ} \mathrm{C}$ por 10 minutos, para todas as variáveis observadas, período de incubação, incidência e severidade (dados não apresentados). As temperaturas e os tempos testados não interferiram no desenvolvimento das mudas, ou seja, não houve fitotoxidade.

O tratamento térmico de bacelos de videira tem sido utilizado com eficiência para erradicação de diferentes fitopatógenos. Mahmoodzadeh et al. (2003), testando diferentes binômios temperatura/ tempo para a erradicação de $R$. vitis de bacelos de videira, variedade Thompson Seedless e portaenxerto NAZ3 (Vitis vinifera x Vitis rupestris), verificaram que $50^{\circ} \mathrm{C}$ por $30 \mathrm{~min}$ erradicou ou reduziu o patógeno a níveis abaixo da detecção, sem prejudicar o desenvolvimento das mudas. No entanto, a sensibilidade de bactérias fitopatogênicas a elevadas temperaturas varia conforme a bactéria estudada. Hao et al. (2012), avaliando o crescimento das espécies Rhizobium tumefaciens 
(sin. Agrobacterium radiobacter), Pectobacterium caratovorum (sin. Erwinia carotovora), Erwinia amylovora, Pseudomonas syringae pv. tomato, Ralstonia solanacearum e $X$. campestris frente a diferentes temperaturas de água, verificaram que os gêneros Ralstonia e Xanthomonas foram os mais resistentes, sendo inativados apenas por $48^{\circ} \mathrm{C}$ durante 24 horas.

No presente trabalho, fatores que podem ter interferido na eficiência das temperaturas e tempos testados, para erradicar as células bacterianas do interior dos bacelos, são o diâmetro e a consistência lenhosa dos mesmos. O primeiro também foi mencionado por Mahmoodzadeh et al. (2003), elevando o tempo que os tecidos internos levam para atingir as temperaturas testadas. Talvez a eficiência desta técnica possa ser melhorada, testando-se maiores tempos de exposição ou usando-se a termoterapia em conjunto com outras práticas, tais como os sanitizantes. Fernandes Jr. et al. (2010) obtiveram $100 \%$ de controle do raquitismo das soqueiras em cana-de-açúcar com o binômio $52^{\circ} \mathrm{C}$ por 2 horas. No entanto, a adição de sanitizantes ao tratamento convencional $\left(52^{\circ} \mathrm{C}\right.$ por 30 minutos $)$ promoveu um controle significativamente maior, diminuindo o tempo de exposição do material ao tratamento térmico.

Nos experimentos com bactericidas em casa de vegetação, não houve diferença significativa entre os tratamentos quanto ao período de incubação, incidência ou severidade da doença (dados não apresentados). No entanto, bacelos tratados com bactericidas em viveiro apresentaram diferença significativa $(\mathrm{P} \leq 0,05)$ para as variáveis analisadas (Tabela 3$)$. Os tratamentos com oxitetraciclina (600 e $700 \mathrm{mg} \mathrm{L}^{-1}$ ) e oxitetraciclina+sulfato de cobre $\left(150+2.000 \mathrm{mg} \mathrm{L}^{-1}\right)$ elevaram significativamente o período de incubação em relação à testemunha. A incidência da doença só foi significativamente menor que a testemunha, quando os bacelos foram tratados com oxitetraciclina (700 mg L $\left.\mathrm{m}^{-1}\right)$. A severidade da doença não foi reduzida pelos antibióticos testados $\mathrm{e}$, ainda, bacelos tratados com oxitetraciclina + sulfato de cobre $\left(165+2.200 \mathrm{mg} \mathrm{L}^{-1}\right)$ apresentaram aumento significativo da severidade (Tabela 3).

$\mathrm{O}$ período de incubação de $X c v$ em mudas de videira 'Red Globe', originadas de bacelos com infecção natural tratados com bactericidas, variou entre 83,1 e 102,3 dias. Essa variável epidemiológica tem influência no número de ciclos das relações patógeno-hospedeiro e, consequentemente, na severidade. Quanto maior o período de incubação, menor será o número de ciclos da doença e menor será a severidade (PARLEVLIET, 1975). No entanto, este fato não apresentou relevância estatística para os tratamentos, que apresentaram o período de incubação significativamente maior em relação à testemunha, mas que não diferiram desta quanto à severidade (Tabela 3).

A redução significativa da incidência da doença com oxitetraciclina (700 $\left.\mathrm{mg} \mathrm{L}^{-1}\right)$ não demonstrou a erradicação do patógeno no interior dos bacelos de videira, uma vez que neste tratamento $20 \%$ das plantas expressaram sintomas da doença. Antibióticos foram muito utilizados na agricultura para o controle de fitobacterioses. No entanto, pesquisas mais recentes têm demonstrado a eficiência duvidosa destes produtos. Um das explicações, além da existência de isolados resistentes, é a rápida multiplicação do patógeno que coloniza os espaços intercelulares e o tecido vascular dos órgãos da videira (NASCIMENTO; MARIANO, 2004), bem como ausência de absorção dos produtos pelos órgãos vegetais e lixiviação pela água de irrigação ou chuva, pois são solúveis em água (ROMEIRO, 2005). Além disso, nem sempre há correlação entre os resultados obtidos in vitro e in vivo, a exemplo do presente trabalho, onde os bactericidas in vitro foram eficientes na inibição de $X c v$ (Tabela 1) e não reduziram a severidade da doença em condições de viveiro (Tabela 3) ou de casa de vegetação. Sugerese ainda que os bactericidas não tenham alcançado o parênquima xilemático infectado por $X c v$, ou que as dosagens testadas não tenham sido suficientes para a erradicação das células bacterianas neste ambiente.

Dos sanitizantes testados, o hipoclorito de sódio ( 10.000 e $\left.12.500 \mu \mathrm{L} \mathrm{L}^{-1}\right)$ causou fitotoxidade às mudas de videira. No experimento em casa de vegetação, as plantas cultivadas não apresentaram diferença significativa entre os tratamentos para as variáveis analisadas (dados não apresentados), ao contrário do que foi observado no experimento em viveiro (Tabela 4). O período de incubação não foi aumentado significativamente pelo tratamento dos bacelos com os sanitizantes, e, além disso, as plantas originadas de bacelos tratados com cloreto de benzalcônio, em quatro das cinco concentrações testadas, apresentaram períodos de incubação significativamente menores, em comparação com a testemunha (Tabela 4). As variáveis incidência e severidade da doença não foram reduzidas pelos tratamentos testados. Em contraposição, plantas originadas dos bacelos tratados com cloreto de benzalcônio (167; 334 e $\left.500 \mu \mathrm{L} \mathrm{L}^{-1}\right)$ apresentaram aumento na incidência da doença e na concentração $167 \mu \mathrm{L} \mathrm{L}^{-1}$, aumento na severidade da doença (Tabela 4). Esse produto testado no controle preventivo da seca dos ponteiros da goiabeira não reduziu 
significativamente nem tampouco aumentou a porcentagem de ramos infectados por Erwinia psidii (REZENDE et al., 2008). O cloreto de benzalcônio é uma amônia quaternária que atua internamente na planta através da indução de mecanismos de defesa, como o aumento do teor de compostos fenólicos, além da síntese de $\beta$-1,3-glucanases e quitinases no tecido vegetal, conferindo uma proteção local, não sistêmica (MARTINS et al., 2009).

Em campo, a pulverização de sanitizantes como protetores contra o agente do cancro bacteriano da videira é uma estratégia que está sendo utilizada pelos produtores de uva do Vale do Submédio São Francisco (RODRIGUES et al., 2012), uma vez que o sanitizante clorado possui amplo espectro biocida (REZENDE et al., 2008; MARTINS et al., 2009; PONTES et al., 2012). Contudo, sanitizantes e fungicidas já foram testados para o controle de outros fitopatógenos em bacelos de videira. Gramaje et al. (2009b) avaliaram diferentes fungicidas e sanitizantes para o controle da doença de Petri (Phaeomoniella chlamydospora e Phaeoacremonium spp.) em estacas, durante a fase de hidratação, verificando que, consistentemente, o cloreto de dodecildimetil amônio foi o melhor desinfetante. Alaniz et al. (2011) avaliaram 14 fungicidas e sanitizantes como protetores de ferimentos na fase de propagação para o controle do pé-preto-da-videira (Cylindrocarpum liriodendri e C. macrodidymum) e relataram que todos os produtos testados reduziram a severidade da doença, mas somente quatro, dentre eles o cloreto de dodecildimetil amônio, reduziram significativamente a porcentagem de reisolamento dos patógenos. Desta forma, o cloreto de dodecildimetil amônio foi indicado para ser incluído em programas de manejo integrado para controle das duas doenças fúngicas (ALANIZ et al., 2011). Com relação a fitobacterioses, Xanthomonas spp. agentes causais da mancha bacteriana do tomateiro foram inibidos por cloreto de dodecildimetil amônio in vitro; no entanto, os resultados não se mantiveram in vivo. Este fato foi relacionado à alta volatilidade, fácil degradação ou baixa aderência à superfície vegetal, concluindo-se que, quando o produto tem baixo poder residual na planta, a eficiência de controle da doença pode ser comprometida (PONTES et al., 2012).

Assim como os bactericidas, os sanitizantes testados não foram eficientes para a erradicação de $X c v$ em bacelos de videira, o que pode ser explicado por estes produtos não terem atuado como sistêmicos, não conseguindo atingir $X c v$ que coloniza o xilema da videira, ou por as concentrações não terem sido suficientemente altas para a erradicação.

TABELA 1- Efeito de bactericidas no crescimento in vitro de Xanthomonas campestris pv. viticola.

\begin{tabular}{lc}
\hline \multicolumn{1}{c}{ Bactericida $\left(\mathrm{mg} \mathrm{L}^{-1} \mathrm{de} \mathrm{H}_{2} \mathrm{O}\right)$} & Halo de inibição $(\mathrm{mm})$ \\
\hline Oxitetraciclina (1.000) & $17,35 \mathrm{a}^{1}$ \\
Oxitetraciclina (800) & $16,71 \mathrm{ab}$ \\
Oxitetraciclina (900) & $16,64 \mathrm{ab}$ \\
Oxitetraciclina (700) & $16,24 \mathrm{bc}$ \\
Oxitetraciclina (600) & $15,68 \mathrm{c}$ \\
Oxitetraciclina+sulfato de cobre $(210+2.800)$ & $11,65 \mathrm{~d}$ \\
Oxitetraciclina+sulfato de cobre $(195+2.600)$ & $11,43 \mathrm{de}$ \\
Oxitetraciclina+sulfato de cobre $(180+2.400)$ & $11,30 \mathrm{de}$ \\
Oxitetraciclina+sulfato de cobre $(165+2.200)$ & $10,74 \mathrm{e}$ \\
Oxitetraciclina+sulfato de cobre $(150+2.000)$ & $10,71 \mathrm{e}$ \\
\hline CV $(\%)$ & 2,53
\end{tabular}

${ }^{1}$ Média de cinco repetições. Médias seguidas de letras diferentes na coluna diferem significativamente, pelo teste de Tukey, a $5 \%$ de significância. 
TABELA 2- Efeito de sanitizantes no crescimento in vitro de Xanthomonas campestris pv. viticola.

\begin{tabular}{lc}
\hline \multicolumn{1}{c}{ Sanitizante $\left(\mu \mathrm{L} \mathrm{L}^{-1}\right)$} & Halo de inibição $(\mathrm{mm})$ \\
\hline Cloreto de dodecildimetil amônio (3.000) & $13,10^{1} \mathrm{a}$ \\
Cloreto de dodecildimetil amônio (1.800) & $12,90 \mathrm{ab}$ \\
Hipoclorito de sódio (7.500) & $12,90 \mathrm{ab}$ \\
Cloreto de dodecildimetil amônio (2.400) & $12,40 \mathrm{ab}$ \\
Hipoclorito de sódio (12.500) & $11,70 \mathrm{abc}$ \\
Cloreto de dodecildimetil amônio (600) & $10,60 \mathrm{bcd}$ \\
Hipoclorito de sódio (10.000) & $9,90 \mathrm{cde}$ \\
Cloreto de dodecildimetil amônio (1.200) & $9,40 \mathrm{cde}$ \\
Hipoclorito de sódio (5.000) & $8,40 \mathrm{de}$ \\
Cloreto de benzalcônio (500) & $8,00 \mathrm{e}$ \\
Cloreto de benzalcônio (334) & $5,50 \mathrm{f}$ \\
Cloreto de benzalcônio (125) & $0,00 \mathrm{~g}$ \\
Cloreto de benzalcônio (167) & $0,00 \mathrm{~g}$ \\
Cloreto de benzalcônio (250) & $0,00 \mathrm{~g}$ \\
Hipoclorito de sódio (2.500) & $0,00 \mathrm{~g}$ \\
\hline CV(\%) & 14,13
\end{tabular}

${ }^{1}$ Média de cinco repetições. Médias seguidas de letras diferentes na coluna diferem significativamente, pelo teste de Tukey, a $5 \%$ de significância.

TABELA 3- Efeito do tratamento de bacelos de videira 'Red Globe' com bactericidas no controle do cancro bacteriano, avaliado pelos componentes epidemiológicos da doença, em plantas das 9 às 15 semanas, em condições de viveiro, Embrapa Semiárido, Petrolina-PE.

\begin{tabular}{lccc}
\hline \multicolumn{1}{c}{$\begin{array}{c}\text { TRATAMENTO } \\
\left(\mathrm{mg} \mathrm{L}^{-1}\right)\end{array}$} & $\begin{array}{c}\text { Período de } \\
\text { incubação (dias) }\end{array}$ & $\begin{array}{c}\text { Incidência } \\
(\%)\end{array}$ & $\begin{array}{c}\text { Severidade } \\
(\%)\end{array}$ \\
\hline Oxitetraciclina (700) & $102,3^{1} \mathrm{a}$ & $4,73^{2} \mathrm{~d}$ & $0,19^{2} \mathrm{c}^{3}$ \\
Oxitetraciclina (600) & $101,4 \mathrm{a}$ & $7,70 \mathrm{~cd}$ & $0,62 \mathrm{bc}$ \\
Oxitetraciclina+sulfato de cobre $(150+2.000)$ & $101,2 \mathrm{ab}$ & $11,87 \mathrm{bcd}$ & $1,07 \mathrm{bc}$ \\
Oxitetraciclina+sulfato de cobre (180+2.400) & $97,8 \mathrm{abc}$ & $21,96 \mathrm{bcd}$ & $0,91 \mathrm{bc}$ \\
Oxitetraciclina (800) & $95,9 \mathrm{abc}$ & $20,50 \mathrm{bcd}$ & $1,05 \mathrm{bc}$ \\
Oxitetraciclina+sulfato de cobre (195+2.600) & $95,6 \mathrm{abc}$ & $16,84 \mathrm{bcd}$ & $1,10 \mathrm{bc}$ \\
Oxitetraciclina (900) & $89,6 \mathrm{bcd}$ & $39,29 \mathrm{ab}$ & $1,66 \mathrm{ab}$ \\
Testemunha & $89,5 \mathrm{~cd}$ & $27,27 \mathrm{abc}$ & $1,27 \mathrm{bc}$ \\
Oxitetraciclina+sulfato de cobre $(165+2.200)$ & $83,1 \mathrm{~d}$ & $48,13 \mathrm{a}$ & $3,71 \mathrm{a}$ \\
\hline CV & 12,6 & 86,5 & 48,4 \\
\hline
\end{tabular}

${ }^{1}$ Média de 21 repetições. Médias seguidas de letras diferentes na coluna diferem significativamente, pelo teste de Tukey, a $5 \%$ de significância. ${ }^{2}$ Dados transformados em $\sqrt{\mathrm{x}+0,01}$. 
TABELA 4 - Efeito do tratamento de bacelos de videira 'Red Globe' com sanitizantes, no controle do cancro bacteriano, avaliado pelos componentes epidemiológicos da doença em plantas das 9 às 15 semanas, em condições de viveiro, Embrapa Semiárido, Petrolina-PE.

\begin{tabular}{lccc}
\hline TRATAMENTO ( $\left.\mu \mathrm{L} \mathrm{L}^{-1}\right)$ & $\begin{array}{c}\text { Período de incubação } \\
(\text { dias })\end{array}$ & $\begin{array}{c}\text { Incidência } \\
(\%)\end{array}$ & $\begin{array}{c}\text { Severidade } \\
(\%)\end{array}$ \\
\hline Cloreto de dodecildimetil amônio (3.000) & $100,4^{1} \mathrm{a}$ & $11,25^{2} \mathrm{f}$ & $0,72^{2} \mathrm{e}^{3}$ \\
Hipoclorito de sódio (7.500) & $98,0 \mathrm{ab}$ & $15,90 \mathrm{f}$ & $1,02 \mathrm{de}$ \\
Cloreto de dodecildimetil amônio (1.800) & $95,2 \mathrm{abc}$ & $22,35 \mathrm{ef}$ & $1,65 \mathrm{bcde}$ \\
Hipoclorito de sódio (5.000) & $94,1 \mathrm{abc}$ & $34,59 \mathrm{cdef}$ & $2,27 \mathrm{bcde}$ \\
Testemunha & $93,0 \mathrm{abc}$ & $25,79 \mathrm{def}$ & $2,01 \mathrm{bcde}$ \\
Hipoclorito de sódio (2.500) & $93,0 \mathrm{abc}$ & $17,45 \mathrm{f}$ & $1,23 \mathrm{cde}$ \\
Cloreto de dodecildimetil amônio (2.400) & $92,6 \mathrm{abc}$ & $23,99 \mathrm{ef}$ & $1,94 \mathrm{bcde}$ \\
Cloreto de dodecildimetil amônio (1.200) & $88,3 \mathrm{abcd}$ & $36,00 \mathrm{bcdef}$ & $1,91 \mathrm{bcde}$ \\
Cloreto de dodecildimetil amônio (600) & $82,7 \mathrm{bcd}$ & $47,89 \mathrm{abcde}$ & $2,64 \mathrm{abcde}$ \\
Cloreto de benzalcônio (250) & $78,9 \mathrm{cde}$ & $61,65 \mathrm{abcd}$ & $3,84 \mathrm{abc}$ \\
Cloreto de benzalcônio (334) & $74,4 \mathrm{de}$ & $67,49 \mathrm{abc}$ & $2,86 \mathrm{abcd}$ \\
Cloreto de benzalcônio (500) & $74,4 \mathrm{de}$ & $76,11 \mathrm{ab}$ & $4,08 \mathrm{ab}$ \\
Cloreto de benzalcônio (125) & $74,1 \mathrm{de}$ & $53,34 \mathrm{abcd}$ & $2,97 \mathrm{abcd}$ \\
Cloreto de benzalcônio (167) & $64,7 \mathrm{e}$ & $87,00 \mathrm{a}$ & $6,23 \mathrm{a}$ \\
\hline CV (\%) & 15,14 & 53,81 & 41,90 \\
\hline
\end{tabular}

${ }^{1}$ Média de 14 repetições. Médias seguidas de letras diferentes na coluna diferem significativamente, pelo teste de Tukey, a 5\% de significância. ${ }^{2}$ Dados originais transformados em $\sqrt{ } \mathrm{x}+0,01$ para efeito de análise.

\section{CONCLUSÃO}

Não é possível recomendar um tratamento termoterápico, bactericida ou sanitizante, dentre os testados, capaz de erradicar a bactéria fitopatogênica $X$. campestris pv. viticola de bacelos de videira infectados. Porém, ficou confirmada a grande importância destes órgãos de propagação na disseminação de $X$. campestris pv. viticola.

\section{AGRADECIMENTOS}

Aos produtores de uva do Vale do Submédio São Francisco; à Dra. Valéria Sandra de Oliveira Costa, da Embrapa Semiárido, pelo apoio nos experimentos; à FACEPE, pela concessão da bolsa de Doutorado e Auxílio Mobilidade Discente-AMD; e ao CNPq pelas bolsas de Produtividade em Pesquisa e apoio Financeiro - Proc. 472.555/2009-0.

\section{REFERÊNCIAS}

ALANIZ, S.; ABAD-CAMPOS, P.; GARCÍAJIMÉNEZ, J.; ARMENGOL, J. Evaluation of fungicides to control Cylindrocarpon liriodendri and Cylindrocarpon macrodidymum in vitro, and their effect during the rooting phase in the grapevine propagation process. Crop Protection, Oxford, v.30, n.4, p.489-494, 2011.

FERNANDES JR., A. R.; GANEM JR., E. J.; MARCHETTI L. B. L.; URASHIMA, A. S. Avaliação de diferentes tratamentos térmicos no controle do raquitismo-da-soqueira em cana-deaçúcar. Tropical Plant Pathology, Brasília, v.35, n.1, p.60-64, 2010.

GRAMAJE, D.; ARMENGOL, J.; SALAZAR, D.; LOPEZ-CORTE, I.; GARCIA-JIMENEZ, J. Effect of hot-water treatments above $50^{\circ} \mathrm{C}$ on grapevine viability and survival of Petri disease pathogens. Crop Protection, Oxford, v.28, n.3, p.280-285, 2009a.

GRAMAJE, D.; AROCA, A.; RAPOSO, R.; GARCIA-JIMENEZ, J.; ARMENGOL, J. Evaluation of fungicides to control Petri disease pathogens in the grapevine propagation process. Crop Protection, Oxford, v.28, n.12, p.1091-1097, 2009b. 
HAO, W.; AHONSI, M. O.; VINATZER, B. A.; HONG, C. Inactivation of Phytophthora and bacterial species in water by a potential energy-saving heat treatment. European Journal of Plant Pathology, Dordrecht, v.134, n.2, p.357-365, 2012.

LIMA, M. F.; MASHIMA, C. Tratamento químico e térmico de bacelos de videira infectados com Xanthomonas campestris pv. viticola. Fitopatologia Brasileira, Brasília, v.25, p.324, 2000. Suplemento

MAHMOODZADEH, H.; NAZIMEH, A.; MAJIDI, I.; PAYGAMI, I.; KHALIGHI, A. Effects of thermotherapy treatments on systemic Agrobacterium vitis in dormant grape cutting. Journal of Phytopathology, Berlin, v.151, n.9, p.481-484, 2003.

MALAVOLTA JR., V. A.; ALMEIDA, I. M. G.; SUGIMORI, M. H.; RIBEIRO, I. J. A.; RODRIGUES NETO, J.; PIRES, E. J. P.; NOGUEIRA, E. M. C. Ocorrência de Xanthomonas campestris pv. viticola em videira no Brasil. Summa Phytopathologica, Jaboticabal, v.25, n.3, p.262-264, 1999.

MARTINS, A. N.; SILVEIRA, A. P.; FURTADO, E. L. Avaliação do cloreto de benzalcônio no controle da ferrugem (Hemileia vastatrix Berk. \& Br.) do cafeeiro (Coffea arabica L.). Summa Phytopathologica, Botucatu, v.35, n.2, p.143-145, 2009.

NASCIMENTO, A. R. P.; MARIANO, R. L. R. Cancro bacteriano da videira: etiologia, epidemiologia e medidas de controle. Ciência Rural, Santa Maria, v.34, n.1, p.301-307, 2004.

NASCIMENTO, A. R. P.; MICHEREFF, S. J.; MARIANO, R. L. R.; GOMES, A. M. A. Elaboração e validação de escala diagramática para cancro bacteriano da videira. Summa Phytopathologica, Botucatu, v.31, n.1, p.56-61, 2005.

PARLEVLIET, J. E. Partial resistance of barley to leaf rust. Puccinia hordei I. Effect of cultivar and development stage on latent period. Euphytica, Wageningen, v.24, n.12, p.21-27, 1975.

PEIXOTO, A. R.; MARIANO, R. L. R.; MOREIRA, J. O. T.; VIANA, I. O. Hospedeiros alternativos de Xanthomonas campestris pv. viticola. Fitopatologia Brasileira, Brasília, v.32, n.2, p.161-164, 2007.
PONTES, N. C.; NASCIMENTO, A. R.; VERDÚ, R. O. M.; QUEZADO-DUVAL, A. M. Avaliação do cloreto de dodecildimetil amônio para o controle da mancha bacteriana do tomateiro. Bioscience Journal, Uberlândia, v.28, n.1, p.43-47, 2012.

REZENDE, A. M. F. A.; TOMITA, C. K.; UESUGI, C. U. Fungicidas cúpricos, cloretos de benzalcônio e composto bioativo líquido (Bokashi): fitotoxidade e controle da seca dos ponteiros causada por Erwinia psidii em goiabeiras. Tropical Plant Pathology, Brasília, v.33, n.4, p.43-47, 2008.

RODRIGUES NETO, J.; DESTÉFANO, S. A. L.; RODRIGUES, L. M. R.; PELOSSO, D. S.; OLIVEIRA JÚNIOR, L. C. Grapevine bacterial canker in the State of São Paulo, Brazil: detection and eradication. Tropical Plant Pathology. Brasília, v.36, n.1, p.42-44. 2011.

RODRIGUES, R. R.; NAUE, C. R.; COSTA, V. S. O.; BATISTA, D. C.; BARBOSA, M. A. G. Inibição do crescimento de Xanthomonas campestris pv. viticola por sanitizantes. In: JORNADA DE INICIAÇÃO CIENTÍFICA DA EMBRAPA SEMIÁRIDO, 7.; JORNADA DE INICIAÇÃO CIENTÍFICA DA FACEPE/UNIVASF, 1., 2012. Petrolina. Anais... Petrolina: Embrapa Semiárido, 2012. p.307-312.

ROMEIRO, R. S. Antibióticos e seu emprego em pesquisa com bactérias fitopatogênicas. In: ROMEIRO, R. S. (Ed.). Métodos em Bacteriologia de Plantas. Viçosa: UFV, 2005. p.127-162.

SILVA, A. M. F.; MELO, N. F.; SOUZA, E. B.; COELhO, A. K.; MARIANO, R. L. R. Limpeza clonal de mudas de videira infectadas por Xanthomonas campestris pv. viticola. Revista Brasileira de Fruticultura, Jaboticabal, v.35, n.1, p.316-319, 2013.

SILVA, A. M. F.; MENEZES, E. F.; SOUZA, E. B.; MELO, N. F.; MARIANO, R. L. R. Sobrevivência de Xanthomonas campestris pv. viticola em tecido infectado de videira. Revista Brasileira de Fruticultura, Jaboticabal, v.34, n.3, p.757-765, 2012.

TOMAZ, R.; SCREMIN, R. M.; FERREIRA, M. A. S. V.; BARBOSA, M. A. G. Detecção e erradicação de videiras com sintomas do cancro bacteriano no Estado do Paraná. Tropical Plant Pathology, Brasília, v.36, p.896, 2011. Suplemento 